The Egyptian Journal of Hospital Medicine (January 2019) Vol. 74 (3), Page 593-601

\title{
Evaluation of Double Face Preputial Flap for Management of Hypospadias in Children
}

\author{
Mohammed El-Sayed Radwan, Mohammed Abdel Razek Desoky, Ahmed Abdel Raouf \\ Abdel Monem Shabaan \\ Department of General Surgery and Pediatric Surgery, Faculty of Medicine, Al-Azhar University
}

Corresponding author: Ahmed Abdel Raouf Abdel Monem Shabaan, Mobile:

(020)01026432982, E-Mail: ahmedra2of1982@gmail.com

\begin{abstract}
Background: hypospadias is a congenital anomaly in which meatal orifice opens in the vental aspect of penis instead of the glans tip. The meatal orifice may be located anywhere between the tip of the penis and the perineum. Objective: the aim of this study was to evaluate double face preputial flap for management of hypospadias in children about success rate, cosmetic result and appearance of complications such as fistula, strictures or disruption. Methodology: this study was conducted on 30 patients who were suffered from mid penile, proximal penile and peno scrotal hypospadias. The age of our cases at the time of repair were ranged between 4-12.5 years. Results: after finishing results of our study we noticed that was no statistically significant difference between results after double face preputial flap technique and ordinary transverse preputial island flap technique (Duckett's procedure) regarding fistula formation or skin infection. Conclusion: although the incidence of fistula formation was lower than that was reported in the classic Duckett repair, however, there was no statistically significant difference between results of double face preputial flap technique and current Duckett's procedure regard skin disruption and fistula formation.
\end{abstract}

Keywords: double face preputial flap, incidence of fistula

\section{Introduction:}

Hypospadias is one of the most common congenital deformities in humans. Its incidence varies between 1:1000 and 1:100 births. The etiology was not fully understood, but there were theories involving testosterone deficiency, multi-factorial causes, genetic predisposition, tissue remodeling and others $^{(\mathbf{1})}$. Hypospadias repair is a challenging topic of urogenital reconstructive surgery and many different techniques are currently being used ${ }^{(2)}$.

Proximal hypospadias, being identified in $20 \%$ of cases, had a higher incidence of complications. Various surgical techniques had been used to repair proximal hypospadias, including tubularized incised plate and onlay island flap urethroplasty. Urethral plate mobilization and dorsal plication had been used to correct the penile curvature of hypospadias with chordee ${ }^{(3)}$.

The surgical repair of primary hypospadias in childhood may result in late postoperative complications involved the external urinary meatus (Stenosis and retrusive meatus), the urethra (stricture, fistula and diverticulum), the corpora cavernosa (penile curvature, torsion or deformity), the preputial skin or the genitalia. The main causes of these late surgical complications were poorly executed procedures, postoperative infection, wound dehiscence, urine extravasation, hematoma or ischemia or necrosis of transplanted tissues ${ }^{(4)}$.

The term "crippled hypospadias" had been coined for individuals with remaining functional complications after multiple attempts at hypospadias repair. 
This term, however, is somewhat pejorative and should probably be avoided in contemporary discussion of this problem. Men have a very heavy burden of psychological problems related to the complications of failed hypospadias repair $^{(5)}$.

Patients who develop strictures after hypospadias repair as a child pose particular problems for stricture repair. Repairs on these individuals are difficult because of scarring, immobility, inflammation, poor blood supply, as well as penile and urethral shortening from prior surgery ${ }^{(6)}$.

\section{Aim of the work:}

This study aimed to evaluate double face preputial flap for management of hypospadias in children about success rate, cosmetic result and appearance of complications such as fistula, strictures or disruption.

\section{Patients and methods:}

After approval from ethical review committee, a prospective randomized non controlled trial study was conducted in Pediatric Surgery Department in Al-hussain and Said Galal University Hospitals during the period of May 2017 to November 2018. It included 30 patients presented to the outpatient clinics with hypospadias.

Cases were selected according to following inclusion and exclusion criteria:

\section{Inclusion criteria:}

- Patients age will be from 6 months to 6 years old.

- Patients with penoscrotal hypospadias.

- Patients with posterior penile hypospadias (with or without chordee).

- Patients with midpenile hypospadias (with or without chordee).

- All patients with intact prepuce (uncircumcised) without history of previous hypospadiac repair (fresh cases).

Exclusion criteria:

- Recurrent cases.

- Absent prepuce (circumcised cases).

- Distal hypospadias (glandular, coronal, subcoronal, and anterior penile hypospadias).

Preoperative assessment and requirements: History:

- Personal history:

Name Age

Date of birth

Consanguinity

- Chief complaint.

- Present history.

- Family history and consanguinity

- Previous illness.

- Past history.

- Medications.

\section{Examination:}

General examination

- For each patient general examination was done to detect any associated anomalies and asses pre-operatively the general condition of the patients.

\section{Local examination}

- Hypospadiac orifice: site and size

- Prepuce.

- Other congenital anomalies.

- Scrotal and perineal examination

\section{Investigations:}

\section{Laboratory investigations}

Routine laboratory investigations were including

- $\mathrm{CBC}$,

- Coagulation profile (prothrombin time and prothrombin concentration and INR), and

- Urine analysis, culture if needed

- Liver function tests, renal function tests

No routine radiological investigations or scanning (as inguino-scrotal or pelviabdominal ultrasound) were ordered.

Before the procedure, informed written consents were taken from all patients' parents or attending relatives after explaining the nature of the disease, risks and complications of the procedures.

Operative interventions: All cases were 
managed using double face preputial flap technique. After appropriate anesthesia with the patient in supine position and after sterilization and toweling

\section{Operative steps:}

1-Application of traction suture on dorsal part of glans penis by using 4/0 vicryl suture (Fig. 1).

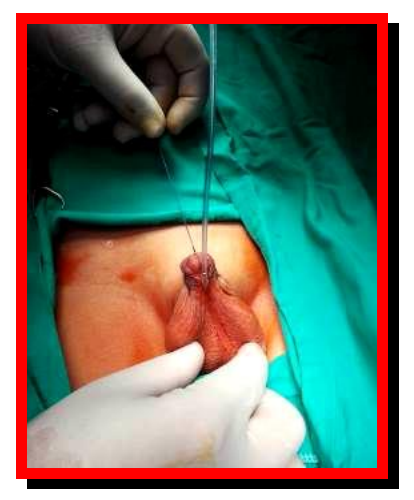

Fig. (1): Application of traction suture.

2- Circumscribing skin incision was made $2 \mathrm{~mm}$ below the coronal sulcus (Fig. 2), after insertion of 8 Fr. Nelaton catheter starting from ventral to dorsal surface of the penis, to confirm that proper width urethral plate was excluded and preserved,

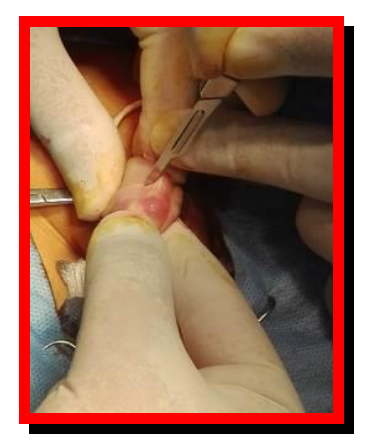

Fig. (2): Skin incision was made $2 \mathrm{~mm}$ below the coronal sulcus.

3- Complete degloving of the penile shaft was done through different planes, ventrally just beneath the skin to penoscrotal junction and dorsally between Bucks and Dartos fasciae to penopubic angle (Fig. 3).
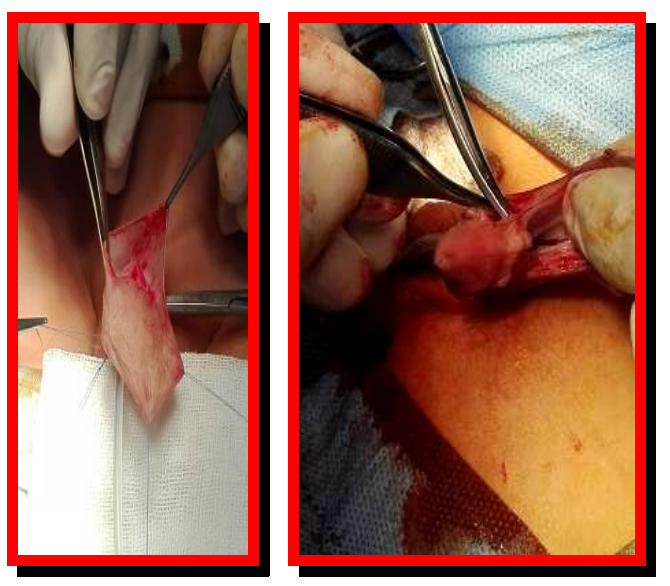

Fig. (3): Complete degloving of the penile shaft.

4- An artificial erection test was performed to ensure proper straightening after degloving.

5- Tourniquet is applied using piece of rubber glove.

6- Preparing of the flap after measurement of the length and supporting with stay sutures (Fig. 4).

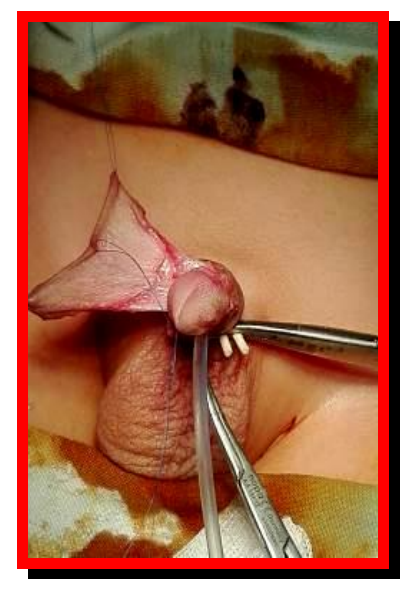

Fig. (4): Preparing of the flap and supporting with stay sutures.

7-Using large Nelaton catheter 10 Fr. For formation of neourethra. The flap was assessed and edges are trimmed and suturing the flap around the nelton catheter using 6/0 Vicryl suture on round needle (Fig. 5). 


\section{Mohammed Radwan et al.}
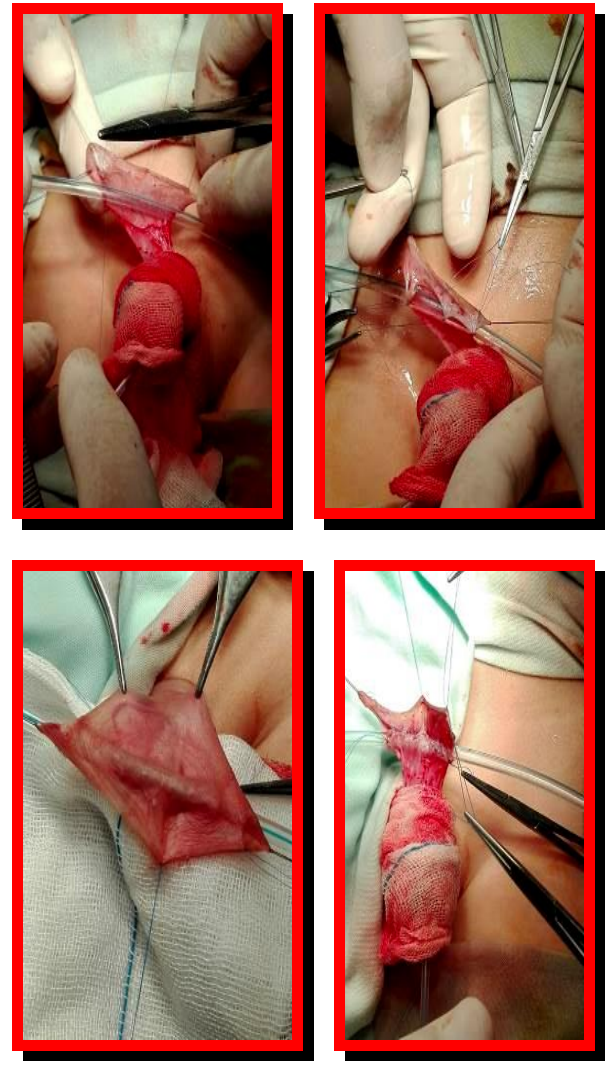

Fig. (5): Formation of neourethra.

8- Flap is rotated anteriorly to the ventral aspect of the penis to be anastmosed to the urethral plate (Fig. 6).
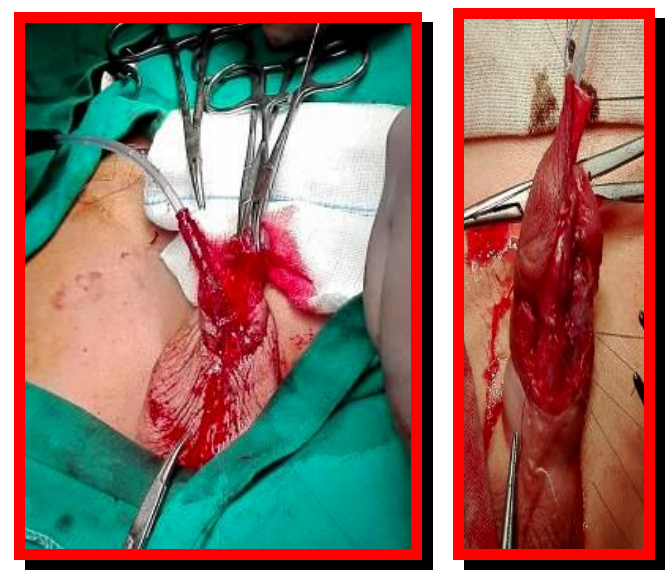

Fig. (6): Rotation of the flap anteriorly to be anastmosed to the urethral plate.

9-Glansoplasty was completed in 2 layers, using 6/0 Vicryl suture starting from corona to distal, with the superficial layer was transverse mattress Catheter was fixed at this stage, using stay suture.

10-Removal of tourniquet to ensure good hemostasis
11- Dressing was accomplished, using SofraTulle with local gentamycin ointment applied around the penis followed by application of Sandwich dressing i.e. phallus was placed between two gauze pieces and placed over anterior abdominal wall with compression applied over gauze (Fig. 7).
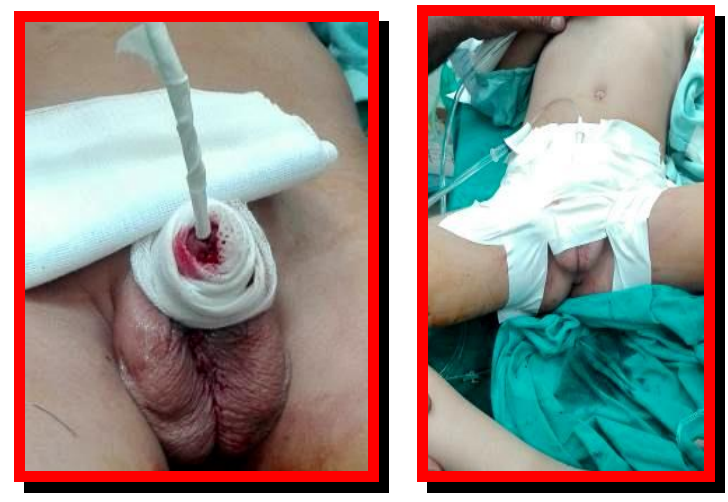

Fig. (7): Application of Sandwich dressing.

\section{Statistical Analysis:}

Recorded data were analyzed using the statistical package for social sciences, version 20.0 (SPSS Inc., Chicago, Illinois, USA). Quantitative data were expressed as mean \pm standard deviation (SD). Qualitative data were expressed as frequency and percentage.

The following tests were done:

- Independent-samples t-test of significance was used when comparing between two means.

- Chi-square $\left(\mathrm{x}^{2}\right)$ test of significance was used in order to compare proportions between two qualitative parameters.

- Receiver operating characteristic (ROC curve) analysis was used to find out the over all predictivity of parameter in and to find out the best cut-off value with detection of sensitivity and specificity at this cut-off value.

- The confidence interval was set to $95 \%$ and the margin of error accepted was set to $5 \%$. So, the p-value was considered significant as the following:

- Probability (P-value) 
Evaluation of Double Face Preputial Flap for Management of Hypospadias in Children

- P-value <0.05 was considered significant.

- P-value >0.05 was considered insignificant.

- P-value $<0.001$ was considered as highly significant.

\section{Results:}

The study subjects included 30 patients of proximal hypospadias whose ages ranged from 6 months to 14 years old and were conducted in Pediatric Surgery Department in Al-hussain and Said Galal University Hospitals during the period of May 2017 to November 2018.All patients were underwent surgical repair by double face preputial flap. The age of our cases at the time of repair were ranged between 4-12.5 years with a mean age of $8.5 \pm 2.4$ years (Table 1).

Table 1: Age distribution of the studied groups

\begin{tabular}{|c|c|c|}
\hline Variable & Range & Mean \pm SD \\
\hline Age (Years) & $4-12.5$ & $8.5 \pm 2.4$ \\
\hline
\end{tabular}

Twenty-eight of our patients $(28 / 30 ; 93.3 \%)$ belonged to the penile hypospadias $56.6 \%$ of these patients (17/30) were mid-shaft hypospadias and $36.7 \%(11 / 30)$ the meatal opening positioned proximally on the penis. The remaining two cases $(2 / 30,6.7 \%)$ the meatal opening present in the penoscrotal junction and the statistical analysis revealed that penil hypospadias was more common in our cases $(\mathrm{P}=0.01)$ (Table 2).

Table 2: Distribution of cases according to the site of the meatus

\begin{tabular}{|l|c|c|c|}
\hline \multicolumn{1}{|c|}{ Type of hypospadias } & No of patients & $\%$ & P \\
\hline Penile: & $\mathbf{2 8}$ & $\mathbf{9 3 . 3 \%}$ & \multirow{2}{*}{$\mathbf{0 . 0 1}$} \\
Mid penile & 17 & 56.6 & (S) \\
Proximal penile & 11 & 36.7 & \\
\hline Penoscrotal & $\mathbf{2}$ & $\mathbf{6 . 7 \%}$ & \\
\hline Total cases & $\mathbf{3 0}$ & $\mathbf{1 0 0 \%}$ & \\
\hline
\end{tabular}

In our study; 4 patients $(4 / 30 ; 13.3 \%)$ had mild degree of fibrous chordee, while the absence of chordee is present in the majority of our cases $(26 / 30,86.7 \%)$ and the statistical analysis revealed the predominance of absence of chordee in our group $(\mathrm{p}=0.01)$ (Table 3$)$.

Table 3: Incidence of chordee among cases of the studied group

\begin{tabular}{|l|c|c|c|}
\hline \multicolumn{1}{|c|}{ Presence of chordee } & No of patients & $\%$ & \\
\hline No chordee & 26 & $86.7 \%$ & 0.01 \\
\hline Presence of chorde & 4 & $13.3 \%$ & $($ S) \\
\hline Total cases & 30 & $100 \%$ & \\
\hline
\end{tabular}

In our study; we encountered operative difficulties in 4 patients $(4 / 30 ; 13.3 \%)$ in the form of difficult dissection of the urethral plate or damage of the corporae of the shaft which ld to excess bleeding during operation or formation of hmatoma post-operatively, while the remaining cases $(26 / 30,86.7 \%)$ of our study we didn't encounter any operative difficulties and the statistical analysis revealed the most of our cases passed smoothly during operation $(p=0.01)$ (Table 4). 
Table 4: Operative difficulties among cases of the studied group

\begin{tabular}{|l|c|c|c|}
\hline \multicolumn{1}{|c|}{ Operative difficulties } & No of patients & $\%$ & \\
\hline No operative difficulties & 26 & $86.7 \%$ & \multirow{2}{*}{0.01} \\
\hline Difficult dissection & 4 & $13.3 \%$ & $($ S) \\
\hline Total cases & 30 & $100 \%$ & \\
\hline
\end{tabular}

Seventeen of our cases $(17 / 30,56.7 \%)$ passed smoothly in the post-operative period without complications while thirteen cases of our studied cases $(13 / 30,43.3 \%)$ encountered early postoperative complications the nine of them (9/30, 30\%) complaining of early post operative fistula and were subjected to conservative treatment in this period of follow-up and the remaining four cases $(4 / 30,13.3 \%)$ complaining of superficial skin infection which were treated conservatively by antibiotic and non-steroidal anti-inflammatory drugs (Table 5).

Table 5: Early post-operative complications among cases of the studied group

\begin{tabular}{|l|c|c|}
\hline \multicolumn{1}{|c|}{ Operative difficulties } & No of patients & $\%$ \\
\hline Complete cure & 17 & $56.7 \%$ \\
\hline Fistula formation & 9 & $30 \%$ \\
\hline Superficial skin infection & 4 & $13.3 \%$ \\
\hline Total cases & 30 & $100 \%$ \\
\hline
\end{tabular}

Twenty-four of our cases $(24 / 30,80 \%)$ passed smoothly in the post-operative period without complications while only six cases of our studied cases $(6 / 30,20 \%)$ encountered late post-operative complications in the form of fistula $(6 / 6100 \%)$ that were subjected to a second surgical setting for repair of fistulae and the statistical analysis revealed that most of our cases (80\%) significantly pass smooth in the follow-up period regarding complications rate $(\mathrm{P}=0.01)$ (Table 6).

Table 6: Late post-operative complications among cases of our study group

\begin{tabular}{|l|c|c|c|}
\hline \multicolumn{1}{|c|}{ Operative difficulties } & No of patients & $\%$ & P \\
\hline Complete cure & 24 & $80 \%$ & 0.01 \\
\hline Fistula formation & 6 & $20 \%$ & $($ S) \\
\hline Total cases & 30 & $100 \%$ & \\
\hline
\end{tabular}

\section{Discussion:}

Hypospadias is defined as an incomplete virilization of the genital tubercle leading to an ectopic opening of the urethra on the ventral aspect of the penis anywhere from the glans to the perineum. Its incidence is about $1 / 300$ in live male births. Surgical repair is the mainstream of therapy and one of the most common procedures performed by pediatric urologists. The aim of hypospadias repair is to achieve normal urinary and sexual function with good esthetic result and self-confidence of the child ${ }^{(7)}$.

The surgical aim of hypospadias repair was to construct a straight penis 
with normal looking shape and location of the external meatus which may not interfere with normal coitus and forward directed stream ${ }^{(8)}$. In our study, all patients managed only with double face preputial flap to evaluate this technique, but in other studies they compared preputial flap with other techniques as ${ }^{(\mathbf{9})}$.

In our study, Seventeen of our cases $(17 / 30,56.7 \%)$ passed smoothly in the post-operative period without complications while thirteen cases of our studied cases $(13 / 30,43.3 \%)$ encountered early post-operative complications the nine of them $(9 / 30,30 \%)$ complaining of early post operative fistula and were subjected to conservative treatment in this period of follow-up and the remaining four cases (4/30, 13.3\%) complaining of superficial skin infection which were treated conservatively by antibiotic and non-steroidal antiinflammatory drugs. In the study done by Ludwikowski and González ${ }^{(10)}$ four patients developed urethrocutaneous fistulas from 21 cases managed with double face preputial flap. In another study carried out by Singal et al. (11) on 92 childrens underwent transverse preputial onlay island flap urethroplasty repair for proximal hypospadias (proximal penile, penoscrotal and scrotal), they found $48 \quad(52 \%)$ children required a tunica albuginea plication for chordee correction. In total, $16 \quad(17 \%)$ patients developed 24 complications and 11 children (12\%) required second surgeries: fistula closure in 7 (with meatoplasty in 5), glansplasty for glans dehiscence in 2 and excision of diverticulum in 2 . Two children required a third surgery. Only 5 children had a noticeable penile torsion (less than 30 degree), and 7 had a patulous meatus. This indicates that Transverse preputial onlay island flap urethroplasty can deliver reliable cosmetic and functional outcomes in proximal hypospadias. Another important consideration in the outcome of hypospadias repair is diversion of urine from the site of the newly created urethra thus allowing it to heal completely, and minimizing the incidences of urethrocutaneous fistula, urethral stenosis or complete breakdown of the repair ${ }^{(\mathbf{1 2})}$.

In the current study, we used transurethral urinary diversion with Nelaton catheter for different reasons. Most important one is that all-silicone Foley catheters have been shown to be more prone to create cuffing formation that was concluded by Parkin et al. (13) in their study. Other advantages of using the Nelaton catheter were cost effectiveness and accessibility. Unfortunately, silicone urethral Foley catheters can't be obtained easily by every institution. Nelaton catheter acts as a stent as well as urinary diversion. It was noticed that there were no slipping or blockage of the catheters in all cases. As regard stent removal time, in this study all catheters were removed after 7-10 days.

Shenoy et $\boldsymbol{a l}^{(\mathbf{1 4})}$ concluded in his study that there was no difference in fistula rates and post-operative stay in patients in whom stent was removed after 5 days and in patients in whom the stent was kept conventionally for $10-14$ days in cases of proximal hypospadias repairs.One of the most controversial aspects of modern hypospadias surgery is the election of an appropriate wound dressing. Multiple dressings after hypospadias surgery have been previously reported. Dressing prevents postoperative edema and hematoma formation, maintaining the phallus in an upright position.

In a comparative study between non-dressed and dressed hypospadias repair, no major difference was seen in outcome (15). In our study, sandwiched dressing was used which was removed 48 hours post-operatively. We found that dressing by this manner is more comfortable for the patients and more 
stable than if it is applied around penis only. Perioperative and postoperative antibiotics are widely used by pediatric urologists, Practice trends among pediatric urologists suggest that more than $91 \%$ of Society for Pediatric Urology members use antibiotics in hypospadias surgery ${ }^{(\mathbf{1 6})}$.

In our study, all patients received intraoperative Prophylactic systemic antibiotic and continued for seven days postoperatively (dose was adjusted according to the age). Regarding wound infection in our study, there were four cases had very superficial wound infection treated conservatively by antibiotic and non-steroidal antiinflammatory drugs. The penis is a highly vascular organ and if severe infection occurred, this may be due to devascularized tissues due to bad handling of the tissues, closure under tension or hematoma. Meticulous dissection used of fine instruments, good hemostasis, raising flaps with good vascularity, use of less reactive sutures and tension free closure. Respection of all these factors had diminished the rate of infection. In our study no patient was complained post-operative hemorrhage or post-operative edema of the penis. After finishing results of our study we noticed that was no statistically significant diference between results after double face preputial flap technique and ordinary transverse preputial island flap technique (Duckett's procedure) regarding fistula formation or skin infection.

\section{Conclusion:}

Although the incidence of fistula formation was lower than that reported in the classic Duckett repair, however, there was no statistically significant difference between results of double face preputial flap technique and current Duckett's procedure regard skin disruption and fistula formation.

\section{References:}

1. Snodgrass $\mathrm{W}$, Villanueva $\mathrm{C}$ and Bush N (2014): Primary and reoperative hypospadias repair in adults - are results different than in children? J. Urol., 192:1730-1733.

2. Wilkinson DJ, Farrelly $P$ and Kenny SE (2012): Outcomes in distal hypospadias: A systematic review of the Mathieu and tubularized incised plate repairs. J. Pediatr. Urol., 8(3):307-312.

3. Scarpa M, Castagnetti M, Musi L et al. (2009): Is objective assessment of cosmetic results after distal hypospadias repair superior to subjective assessment? J. Pediatr. Urol., 5:110-113.

4. Chadha $A$ and Singh A (2012): The forked flap repair for hypospadias. Indian Plast. Surg. J., 45(3):516-520.

5. Snodgrass $W$ and Yucel $S$ (2007): Tubularized incised plate for mid shaft and proximal hypospadias repair. J. Urol., 177(2):698-702.

6. Rynja SP, De Jong TP, Bosch JL et al. (2011): Functional, cosmetic and psychosexual results in adult men who underwent hypospadias correction in childhood. J. Pediatr. Urol., 7(5):504-515.

7. Baillargeon E, Duan $K$, Brzezinski A et al. (2014): The role of preoperative prophylactic antibiotics in hypospadias repair. Can. Urol. Assoc. J., 8(7-8): 236240.

8. Al-Saied G and Gamal A (2009): Versatility of tubularized incised plate urethroplasty. Afr. J. Paediatr. Surg., 6: 88-92.

9. Sadeghi A and Mirshemiran A (2017): Duckett versus modified bracka technique for proximal hypospadias repair a 10-year 
experience. Iranian Journal of Pediatrics, 27 (6): 7752-7761.

10. Ludwikowski $B$ and González $R$ (2014): Total preputial flap: a reliable and versatile technique for urethral and penile reconstruction. Front. Pediat., 2: 43-46.

11. Singal AK, Dubey $M$ and Jain $V$ (2016): Transverse preputial onlay island flap urethroplasty for single-stage correction of proximal hypospadias. World J. Urol., 34: 1019-1024.

12. Osifo OD and Azeez AL (2010): Outcomes of transurethral and suprapubic urinary diversion following hypospadias repair in children. Pak. J. Med. Sci., 26 (2): 329-334.

13. Parkin J, Scanlan $J$ and Woolley M (2002). Urinary catheter 'deflation cuff' formation: clinical audit and quantitative in vitro analysis. BJU. Int., 90: 666-671.
14. Shenoy NS, Kumbhar VV, Shenoy YR et al. (2016): Outcome of hypospadias repair - stentless versus stented repair. Int. Surg. J., 3:2167-172.

15. Van Savage JG, Palanca LG and Slaughenhoupt BL (2000): A prospective, randomized trial of dressing vs. no dressings for hypospadias repair. J. Urol., 164:981-3.

16. Hsieh MH, Wildenfels $P$ and Gonzales ET (2011): Surgical antibiotic practices among pediatric urologists in the United States. J. Pediatr. Urol., 7(2):192-197. 